The palatability of the diets containing milo corn was confirmed as well as the good behaviour of the pigs in all groups since no statistically significant difference was observed with respect to performances and body composition of the animals during the whole experimental period $(25-103 \mathrm{~kg})$. However, pigs fed with milo corn exhibited a slightly higher food conversion ratio than these fed exclusively with maize.

This reduction of feed efficiency when using milo corn was particularly marked during the growing period, but was entirely compensated for during the finishing period.

The results indicate that milo corn should be used moderately during the growing period, whereas its exclusive use is possible during the whole fattening period. The method of substitution adopted (milo corn equivalent to 92 p. Ioo of the digestible energy value of maize) led to definitely better results than in our previous trial. It seems possible to use this method at least at the present time, until the list of tannin contents of our varietics has been further developed and the balance studies on pigs have been started.

\title{
Eifects of micronizing of maize and wheat on the performances of ad libitum fed pigs
}

\author{
H. TARDIF, M. LEUILLET \\ Union des Fabricants d'Aliments composés, \\ 94450 Vigny \\ Institut Technique des Cévéales et des Fourrages. \\ 8 , avenue du Président Wilson, \\ 75116 Paris
}

According to a common programme established by U.F.A.C. (Union of Compound lieed Producers) and I.T.C.F. (Technical Institute for Cereals and Forages), a series of experiments was conducted simultaneously at Vigny and at Areines (S.F.A.P.) on I92 and I6o pigs, respectively, in order to examine the effect of micronizing of wheat and maize on the performances of ad libitum fed animals.

The results clearly show that the value of the feeds was further improved when the latter had been subjected to two technological treatments (micronization of the cereal followed by granulation of the feed). The effect was particularly marked on growth in the case of wheat $(+\mathbf{I} \cdot+$ p. 100) and on feed efficiency in the case of maize $(7.7$ p. 10o).

In addition, the technological effects seemed to be cumulative since the addition of simple effects led to obtention of the level of improvement allowed by their cumulation.

However, it was noted that granulation alone accounted for the greatest part of the improvement recorded : from 56 to $89 \mathrm{p}$. Ioo for growth and from 67 to $70 \mathrm{p}$. Ioo for feed efficiency, the highest values being obtained with wheat.

From an economic point of view, micronization of wheat or maize intended to be used in ad libitum pig feeding is not interesting since granulation alone allows to obtain almost similar results at definitely lower costs. 